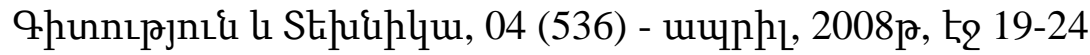

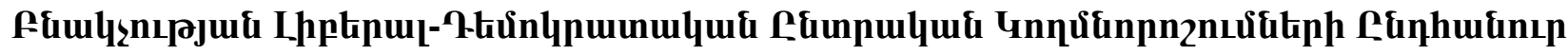

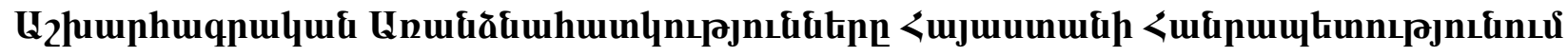

\section{2пцими <nıиhl}

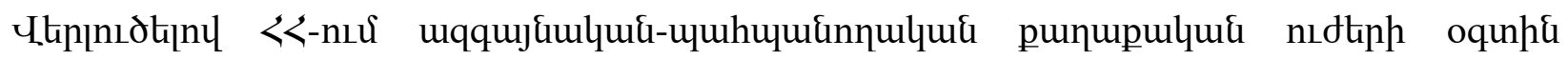

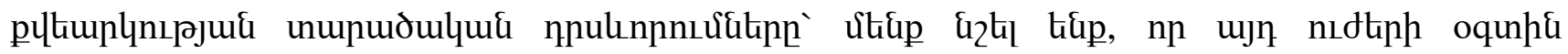

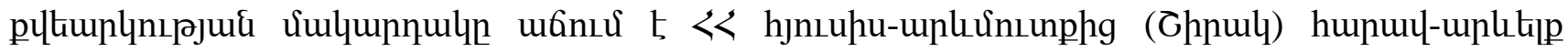

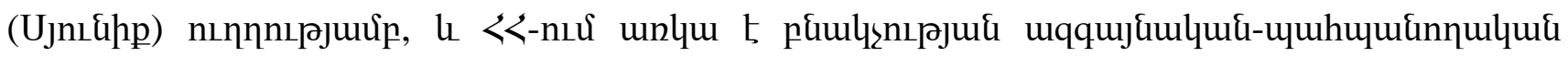

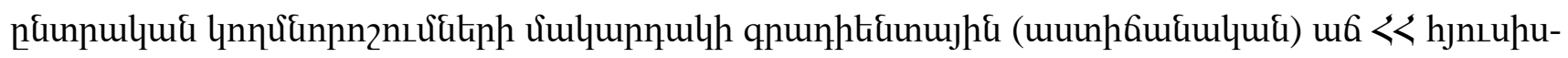

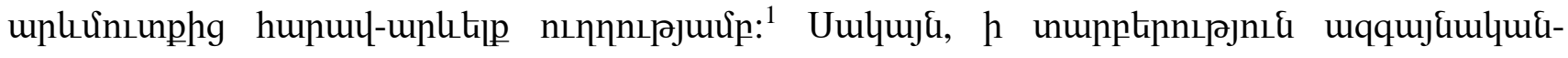

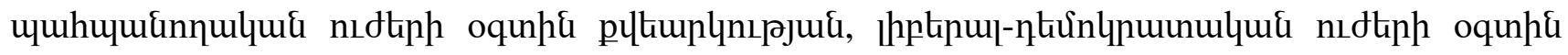

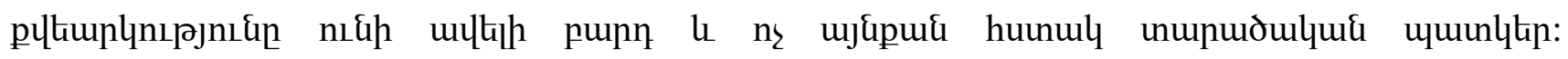

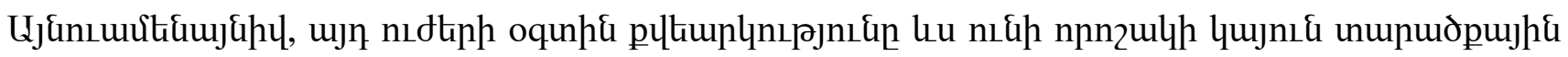

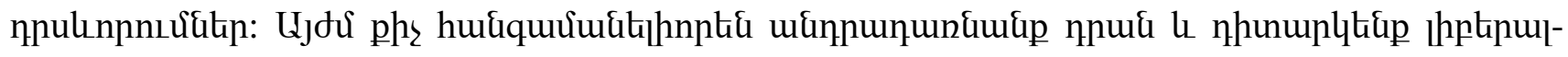

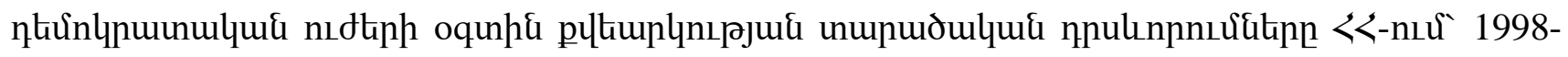

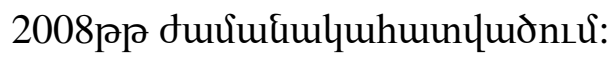

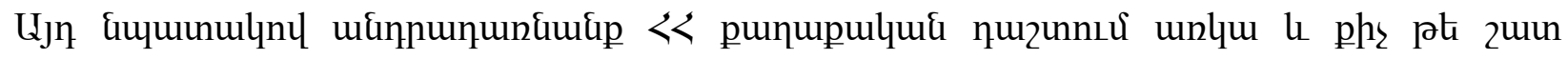

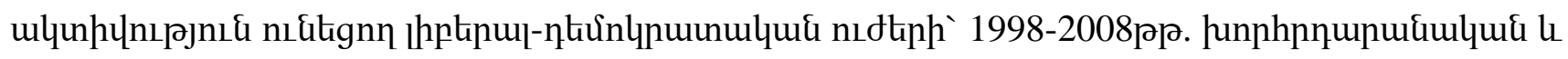

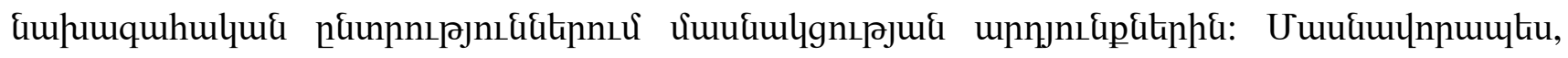

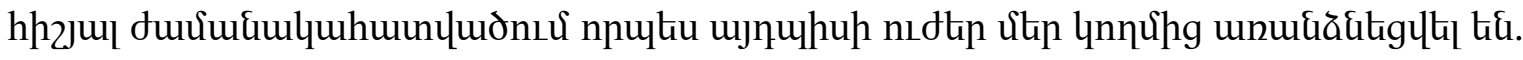

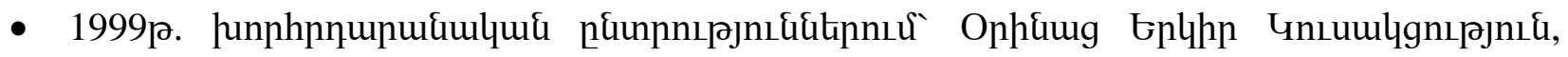

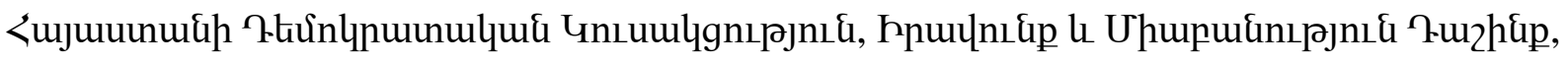

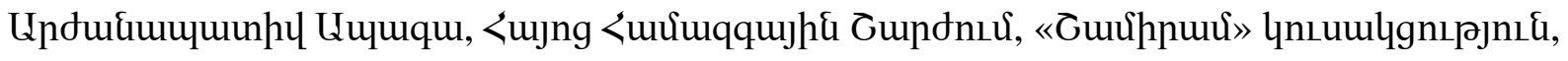

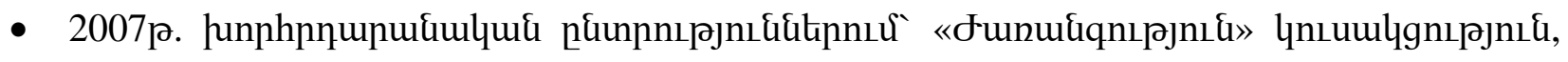

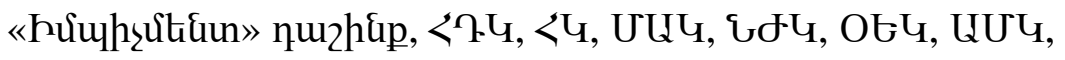

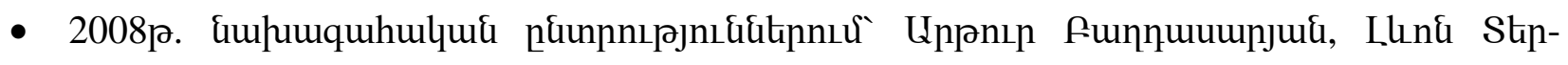
Thunpnujuí:

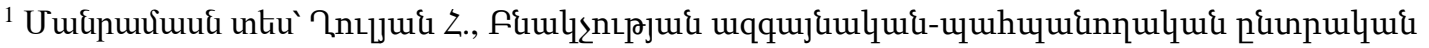

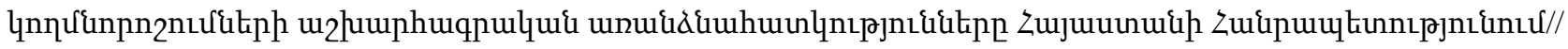

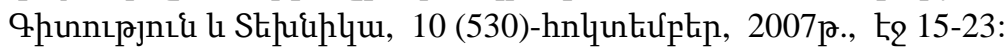




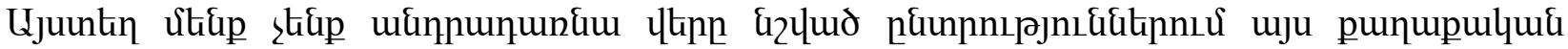

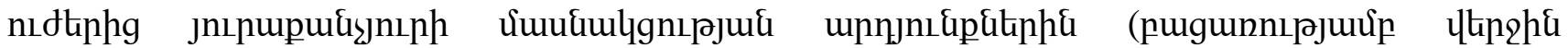

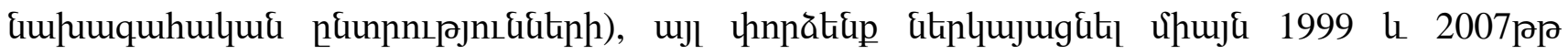

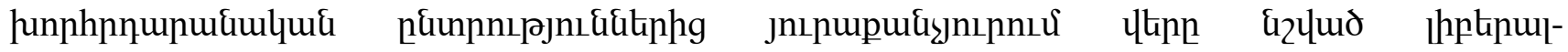

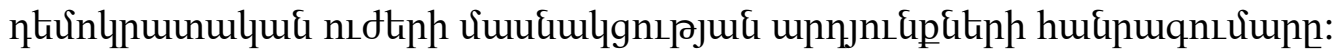

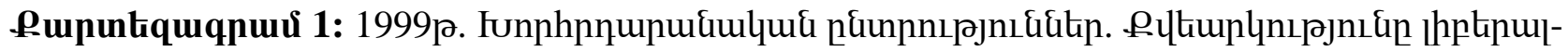

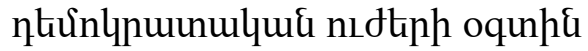

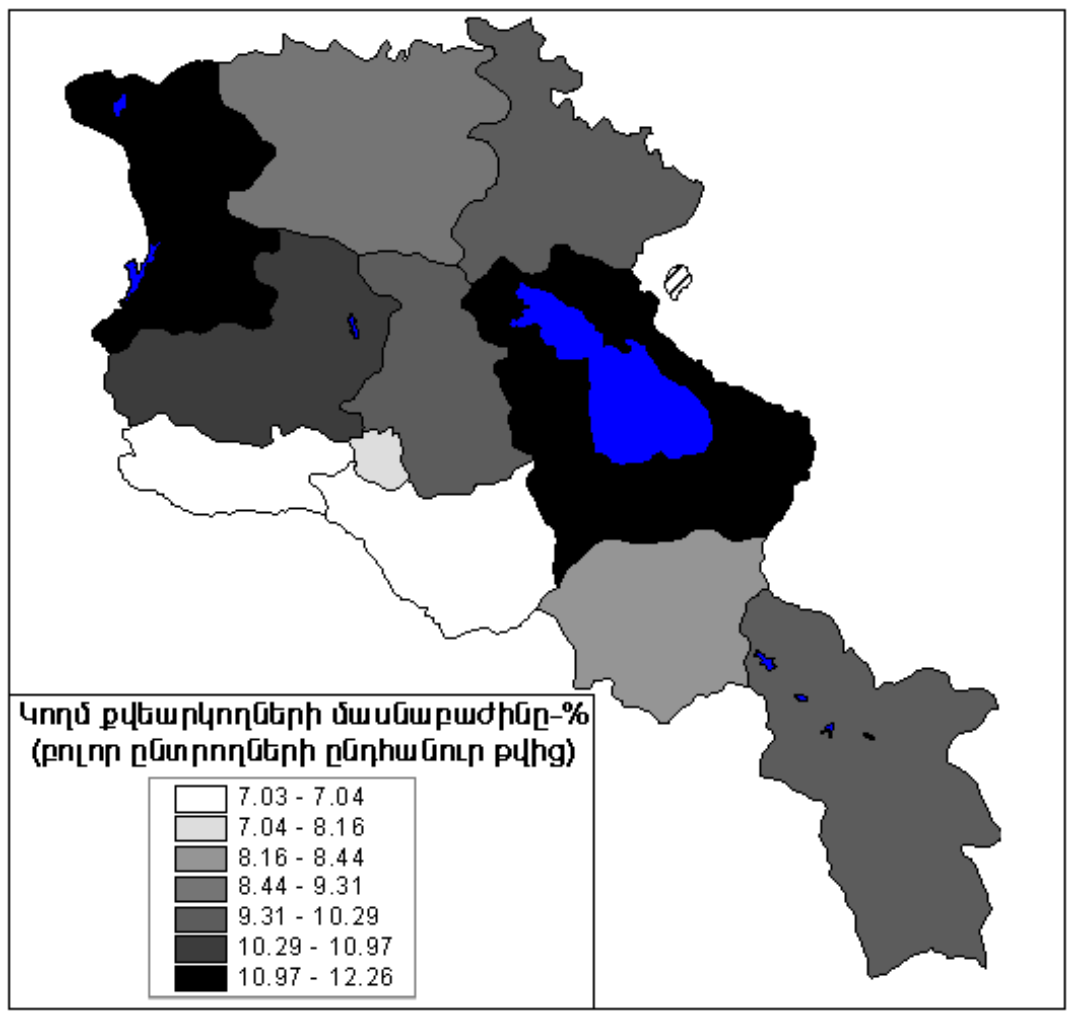

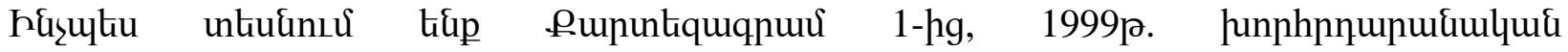

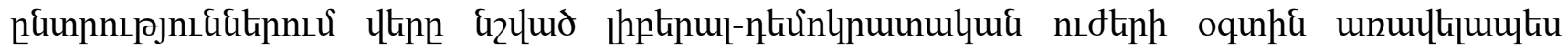

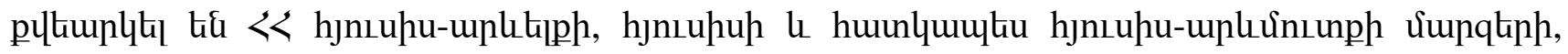

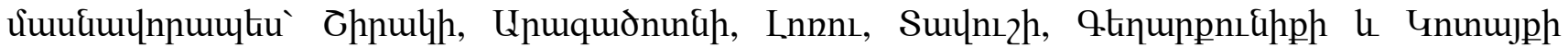

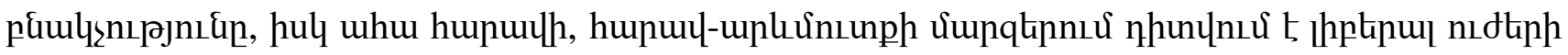

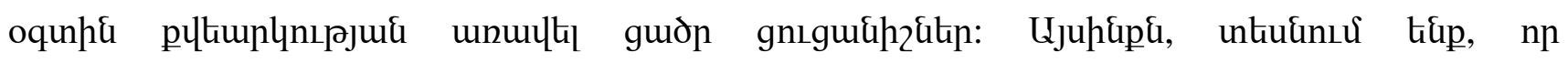

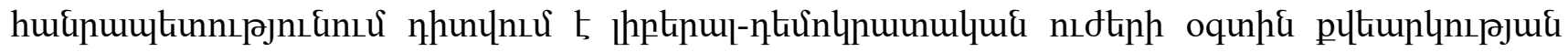

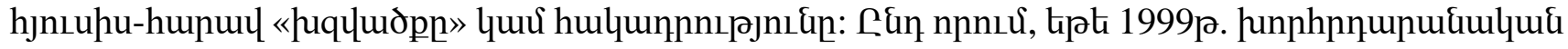

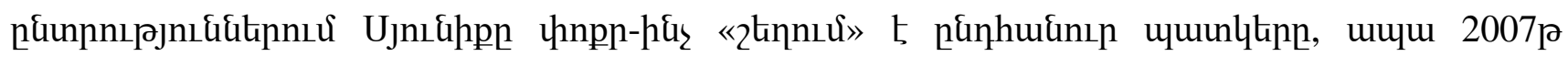




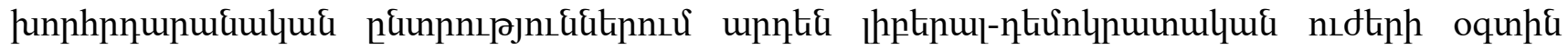

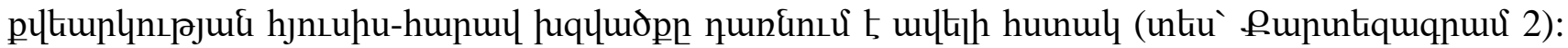

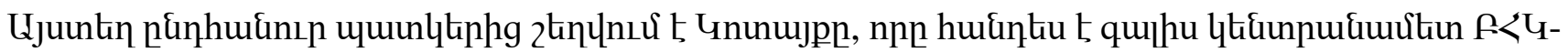

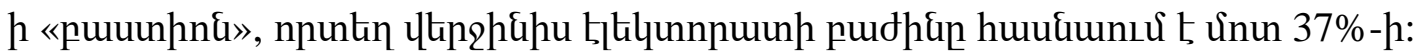

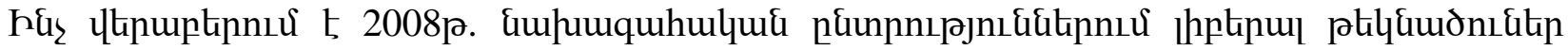

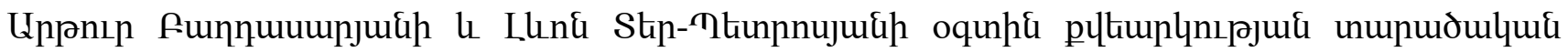

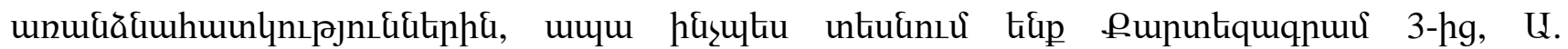

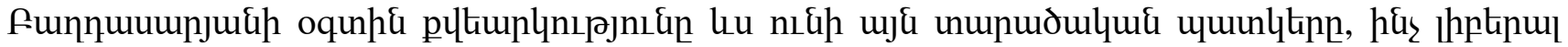

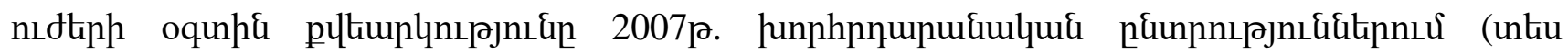

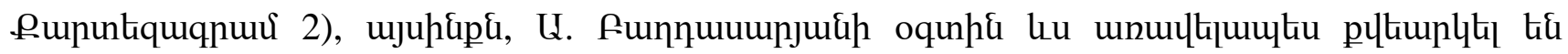

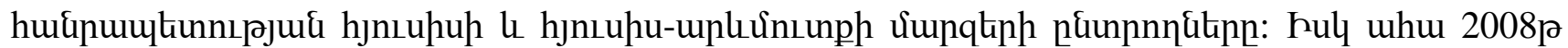

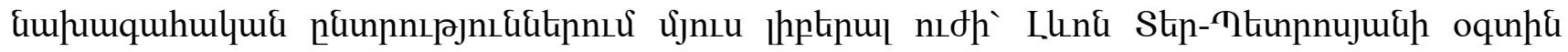

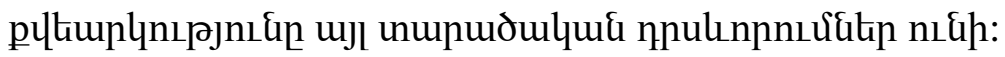

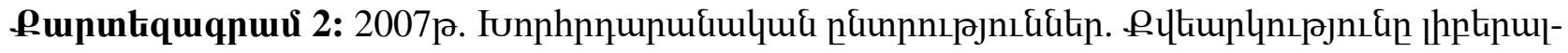

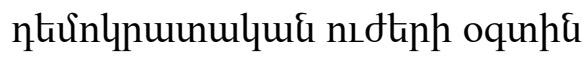

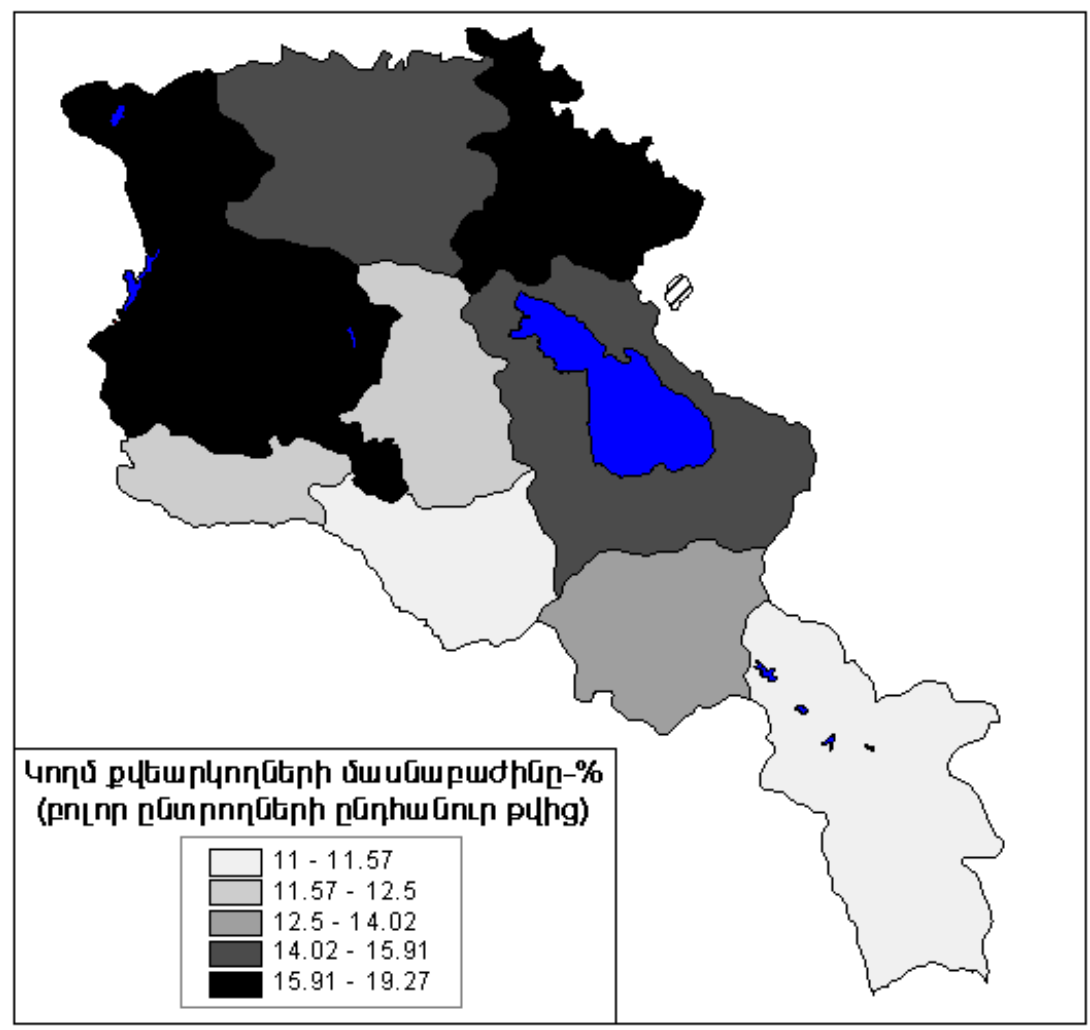




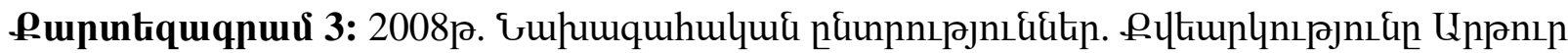

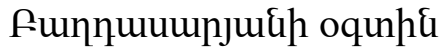

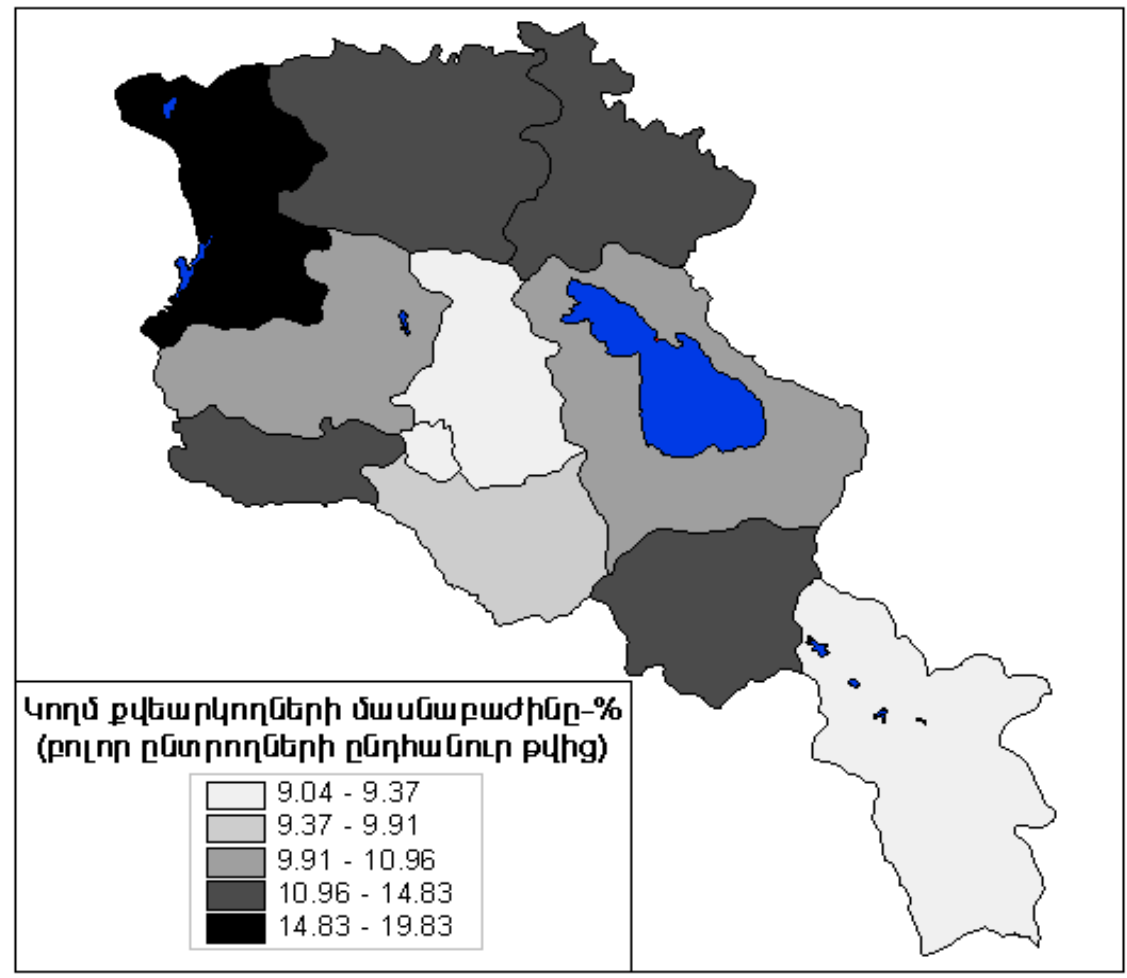

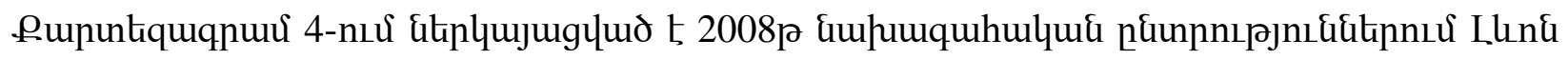

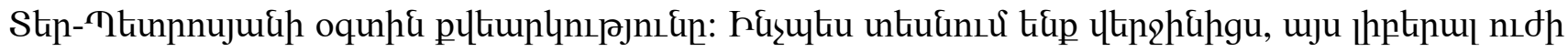

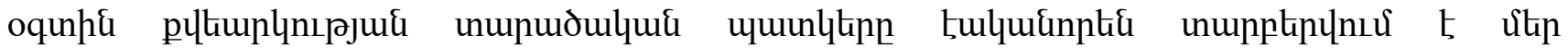

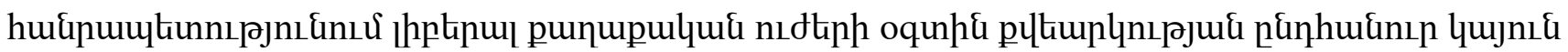

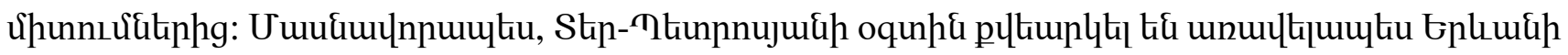

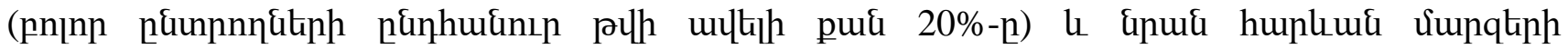

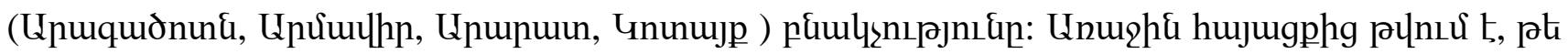

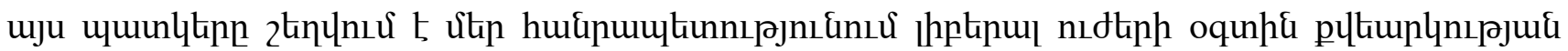

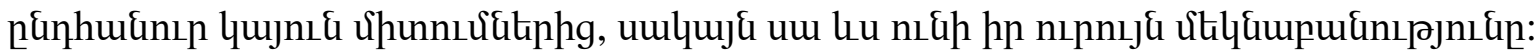

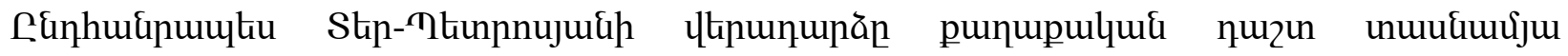

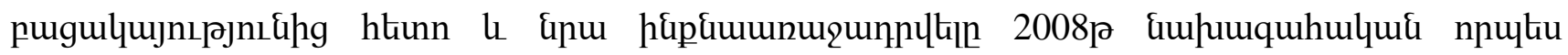

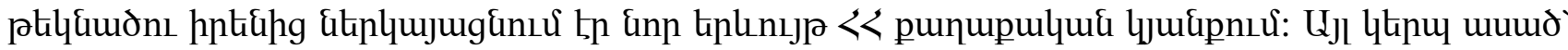

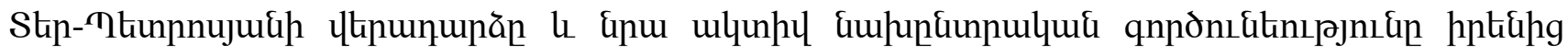

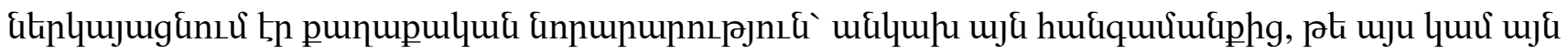

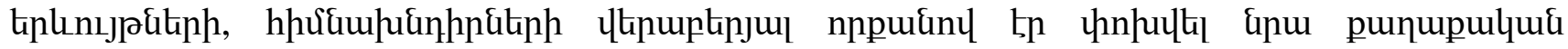




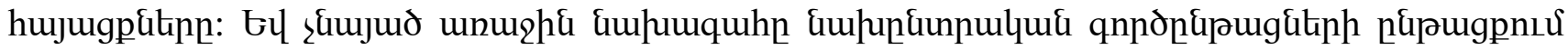

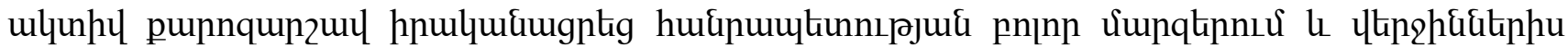

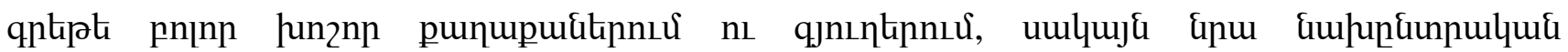

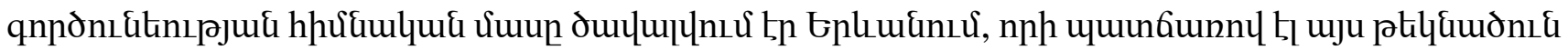

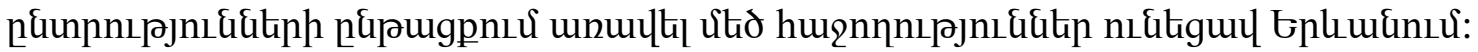

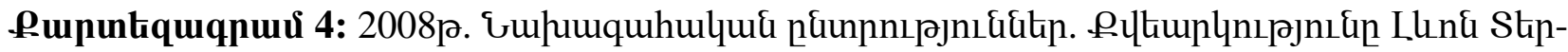
Thinnnujuîh oqunhu

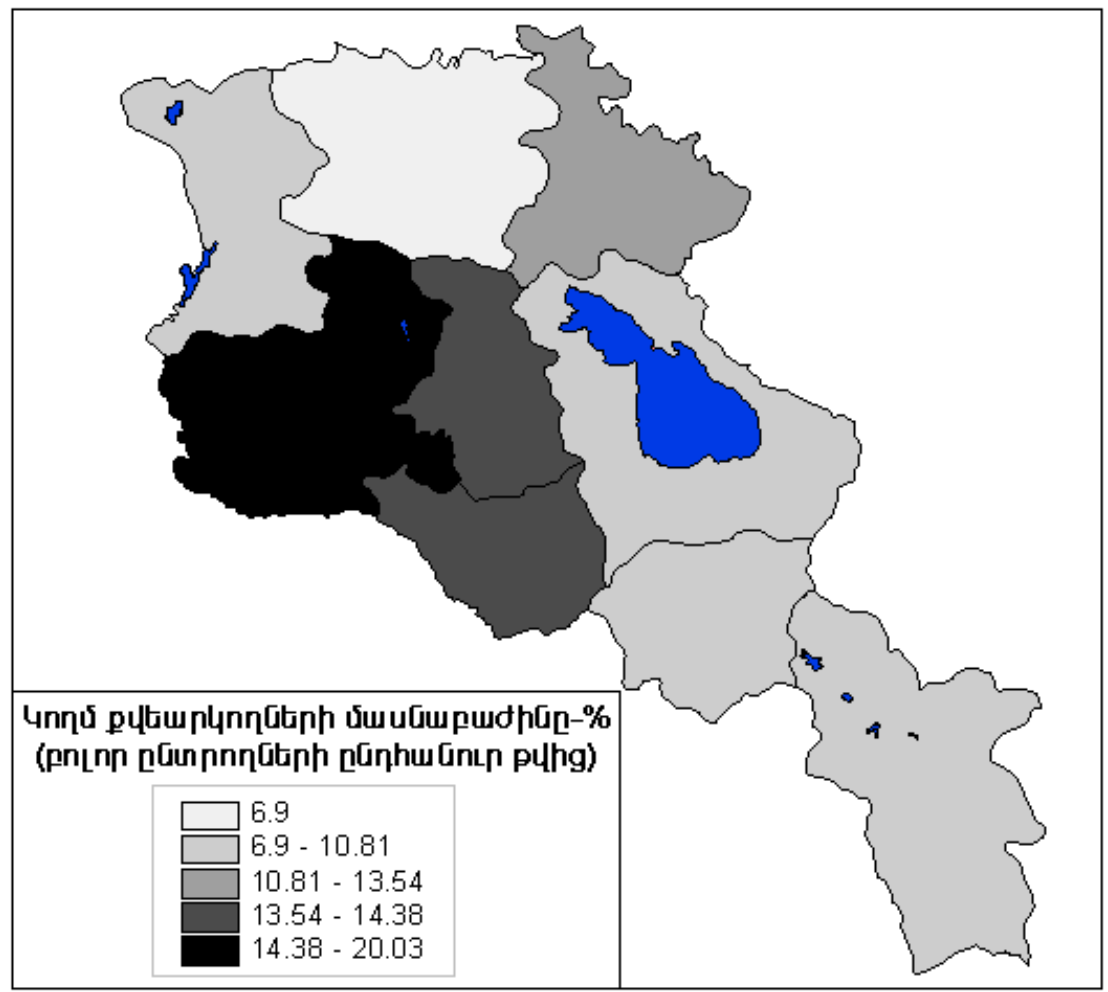

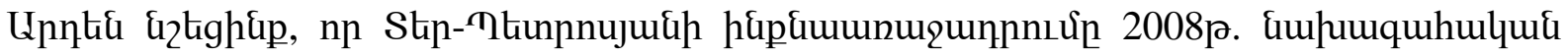

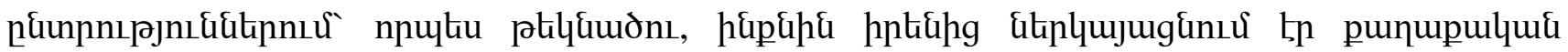

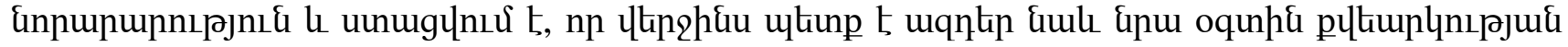

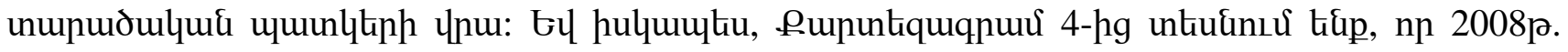

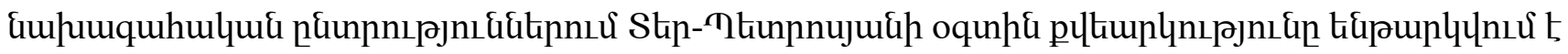

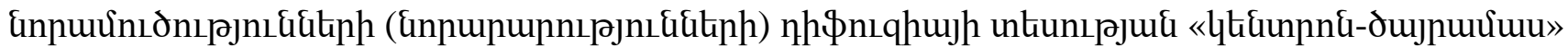
unntiıhน:

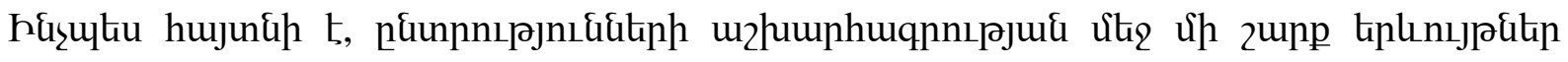

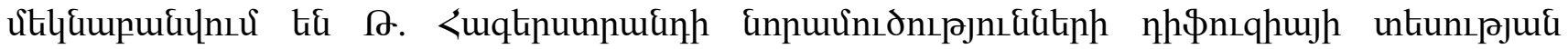




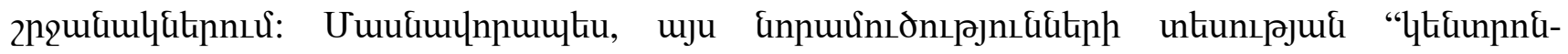

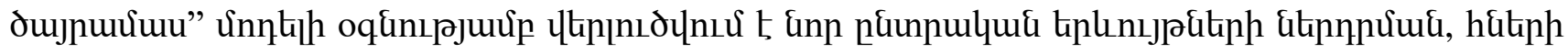

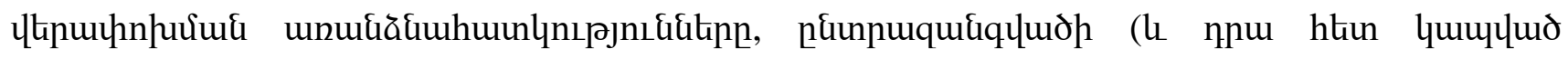

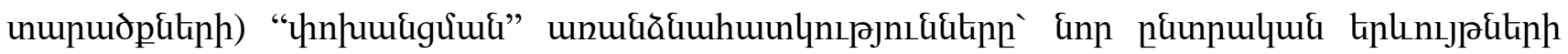

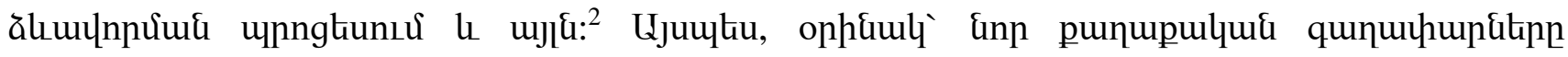

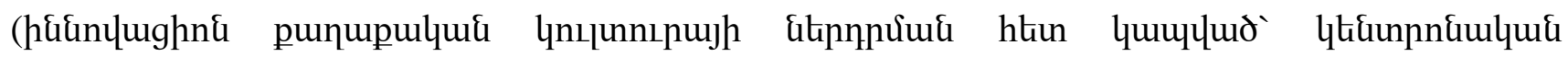

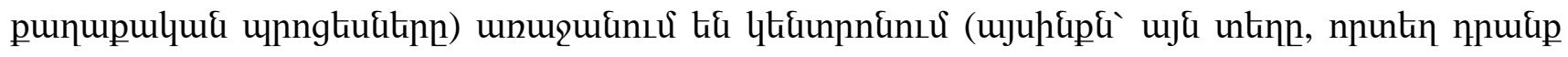

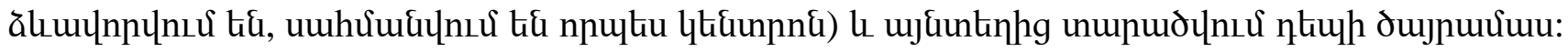

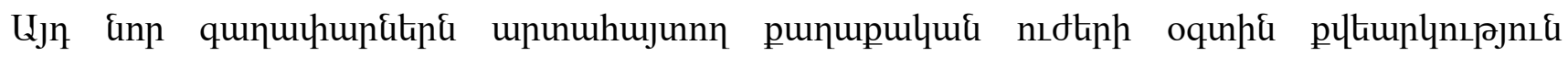

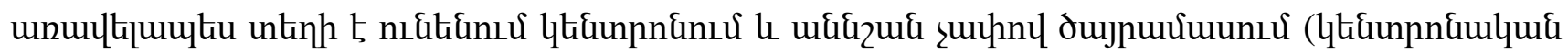

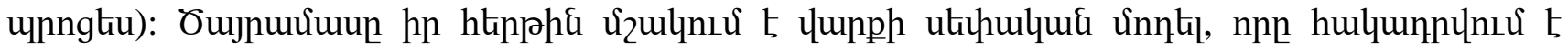

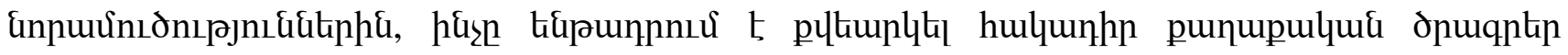

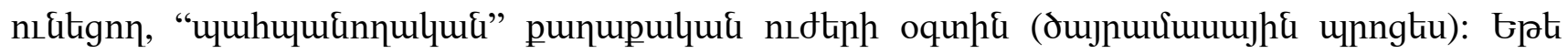

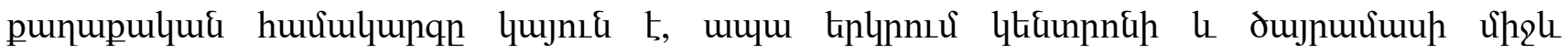

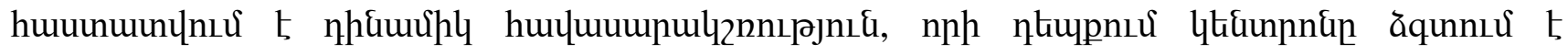

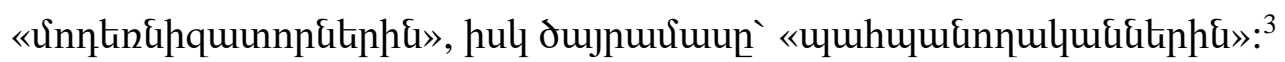

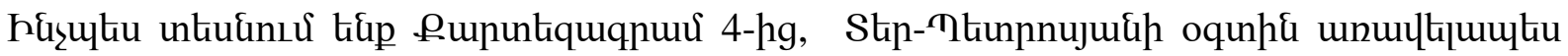

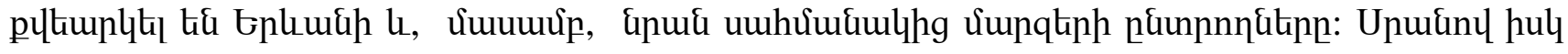

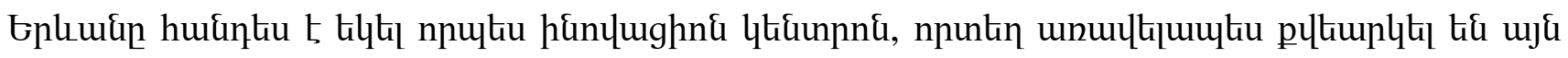

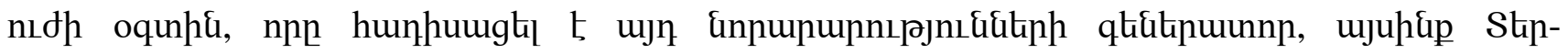

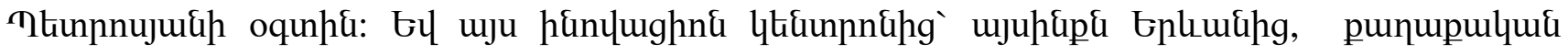

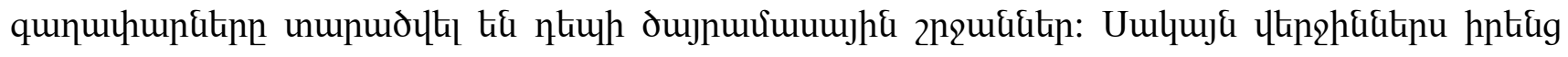

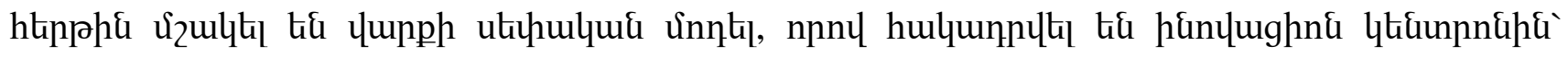

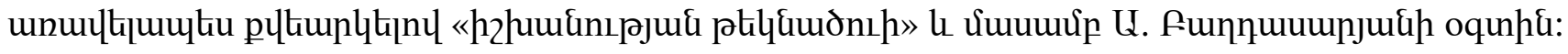

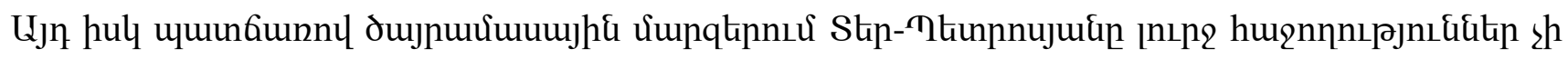
nı\&itigti:

2 Туровский Р.Ф. Региональные аспекты общероссийских выборов// Второй электоральный цикл в России (19992000 гг.). М., Весь мир, 2002, с. 186-214. http://www.electoralgeography.com/docs/turovsky/2002-regional-aspects.doc. ${ }^{3}$ Туровский Р.Ф. Политическое расслоение российских регионов (история и факторы формирования) // Партийно-политические элиты и электоральные процессы в России. Круглый стол бизнеса России. Аналитические обозрения Центра комплексных социальных исследований и маркетинга. Серия: политология. Выпуск 3'96 (17), с.37-2 (раздел V). http: //www.electoralgeography.com/docs/turovsky/rassloenie-region.rtf. 
Qhunnıpjnı\& lu Stihuquluu, 04 (536) - uuuphı, 2008p, te 19-24

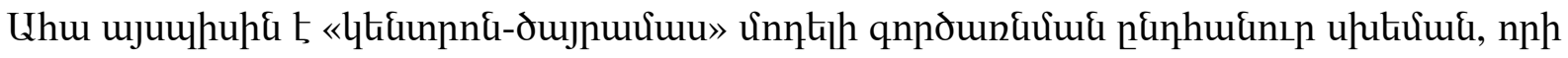

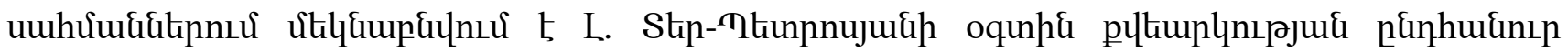

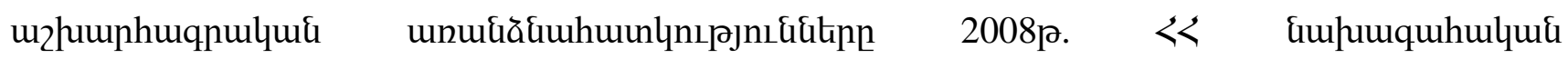

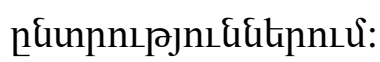

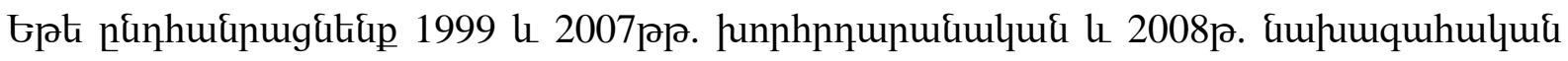

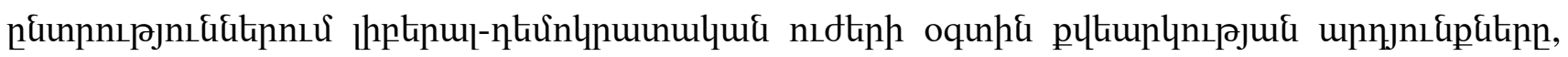

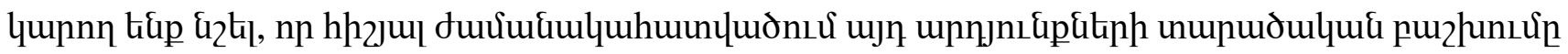

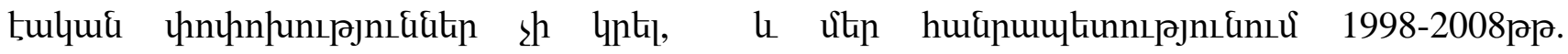

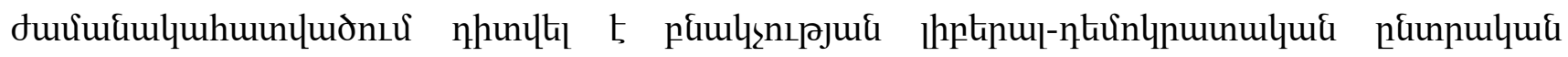

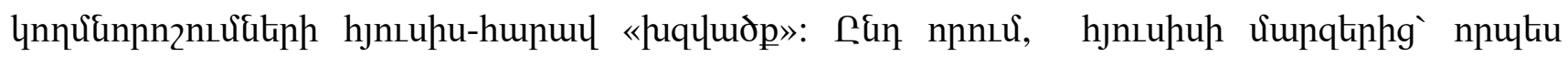

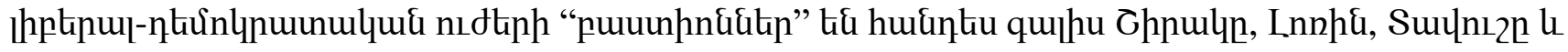

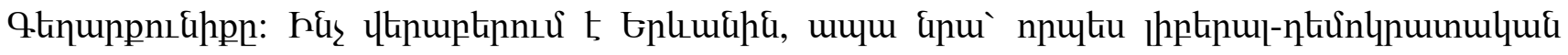

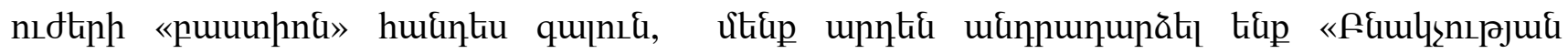

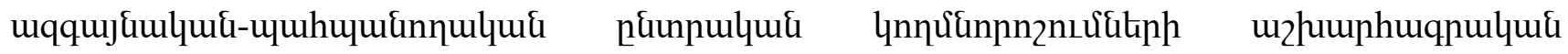

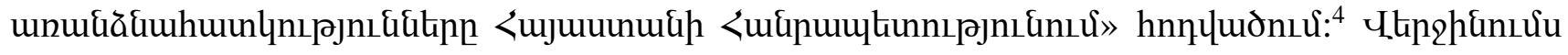

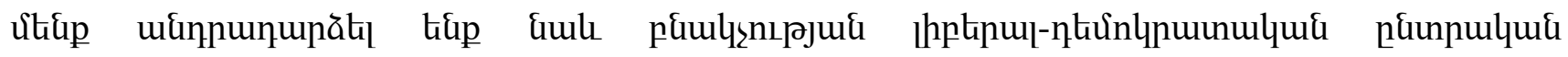

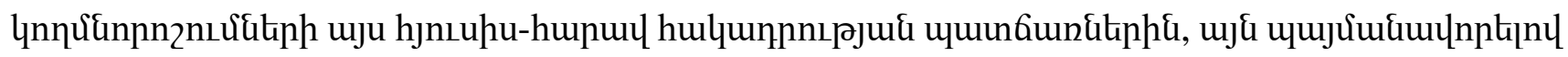

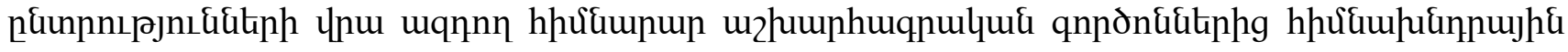

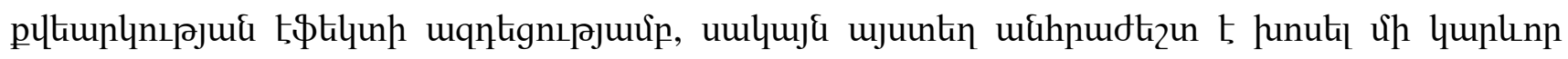

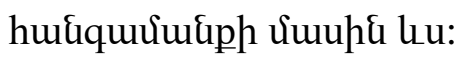

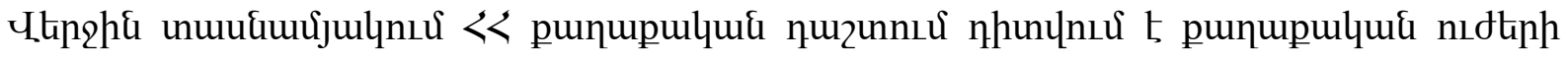

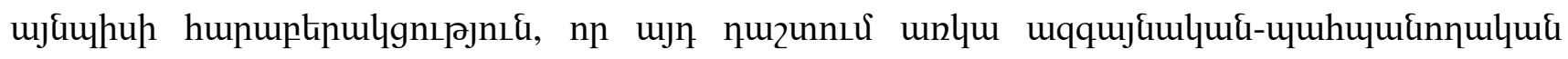

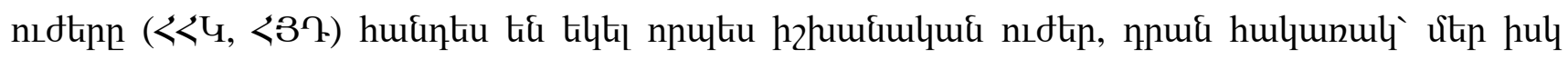

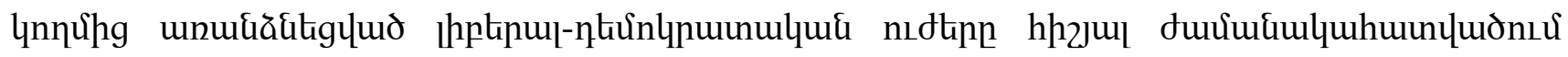

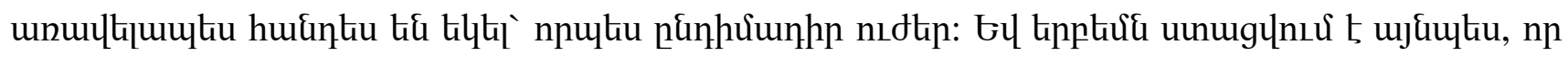

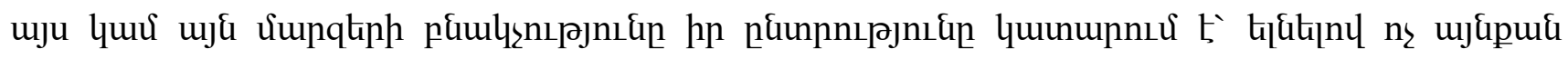

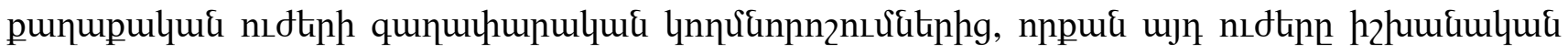

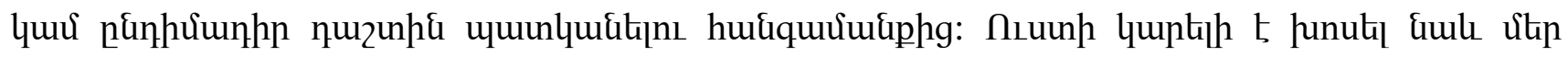

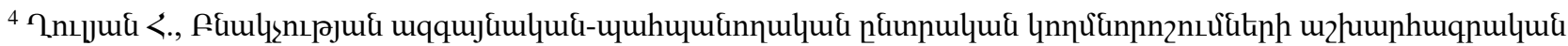

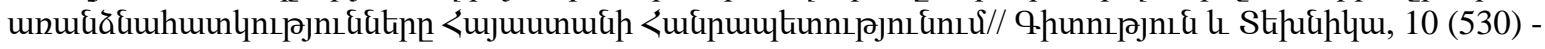
hnlunkiuptip, 2007p., ts 15-23:
} 


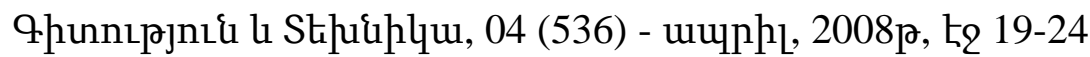

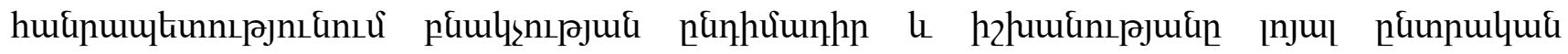

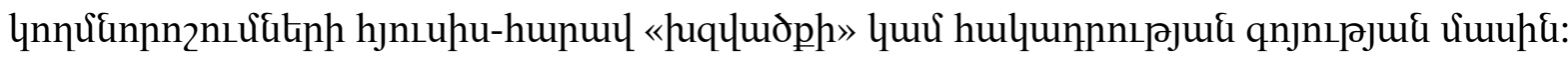

\section{Q.pulquinıpjnı\&}

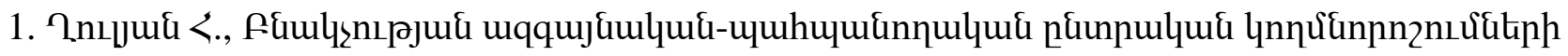

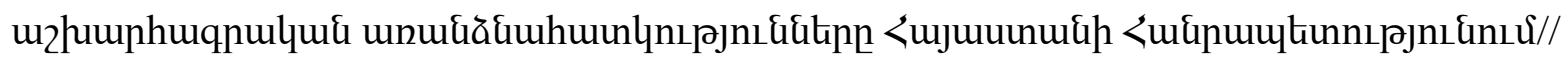

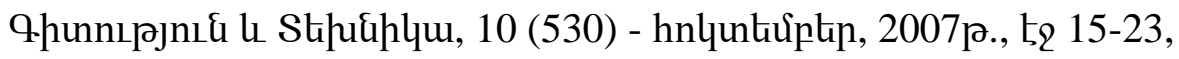

2. Туровский Р.Ф. Региональные аспекты общероссийских выборов// Второй электоральный цикл в России (1999-2000 гг.). М., Весь мир, 2002, с. 186-214. http://www.electoralgeography.com/docs/turovsky/2002-regional-aspects.doc,

3. Туровский Р.Ф. Политическое расслоение российских регионов (история и факторы формирования) // Партийно-политические элиты и электоральные процессы в России. Круглый стол бизнеса России. Аналитические обозрения Центра комплексных социальных исследований и маркетинга. Серия: политология. Выпуск 3'96 (17), с.37-2 (раздел V). http: //www.electoralgeography.com/docs/turovsky/rassloenie-region.rtf, 


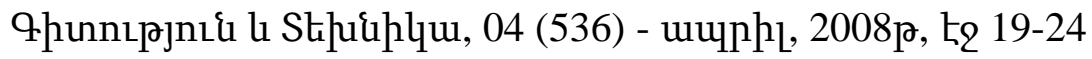

Гулян Усик

ОБЩЫЕ ГЕОГРАФИЧЕСКИЕ ОСОБЕННОСТИ НАЦИОНАЛЬНО-КОНСЕРВАТИВНЫХ ЭЛЕКТОРАЛЬНЫХ ПРЕДПОЧТЕНИЙ НАСЕЛЕНИЯ В РЕСПУБЛИКЕ АРМЕНИЯ

Цель статьи выявление и интерпретация географических особенностей либеральнодемократических электоральных предпочтений населения в Республике Армения. Для этого анализировалось структура политического пространства РА в 1998-2008гг. и существование в этом пространстве политических сил разных идеологических ориентаций. Для выявления географических особенностей либерально-демократических электоральных предпочтений населения, анализировалось результаты участия либерально-демократических политических сил (партий и кандидатов) в президентских и парламентских выборах последнего десятилетия. В итоге с помощью сопоставления и пространство-временного анализа итогов парламентских и президентских выборов, автор пришел к выводу, что в РА при голосовании за либеральнодемократических политических сил существует раскол 'север-юг' при котором население северных регионов (марзов) голосует преимущественно за либерально-демократических политических сил, а население южных регионов голосует преимущественно за национальноконсервативных политических сил.

Ghulyan Husik

GENERAL GEOGRAPHICAL FEATURES OF LIBERAL-DEMOCRATIC ELECTORAL PREFERENCES OF POPULATION IN THE REPUBLIC OF ARMENIA

The purpose of this article is to reveal and analyze the general geographical features of liberaldemocratic electoral preferences of the population in the Republic of Armenia, therefore, the structure of political landscape of RA for 1998-2008 period and the existence of political forces with different ideological orientation in this landscape has been analyzed. In order to reveal the geographical features of liberal-democratic electoral preferences of the population, the voting for liberal-democratic political forces at presidential and parliamentary elections of the last decade have been analyzed. As a result of the comparative and spatiotemporal analysis, the papers concludes that in RA in the voting for liberaldemocratic political forces there is a north-south 'cleavage', namely the population of northern regions votes mainly for liberal-democratic political forces, while the population of the southern regions mainly votes for national-conservative ones. 